\title{
PENGEMBANGAN LEMBAR KEGIATAN SISWA (LKS) BERBASIS INKUIRI STUDI KASUS PEMBELAJARAN DI KELAS X SMAN 6 METRO TAHUN PELAJARAN 2013/2014
}

\author{
Novarati Andarika ${ }^{1}$ \\ Hening Widowati ${ }^{2}$ \\ 1,2 Pendidikan Biologi FKIP Universitas Muhammadiyah Metro \\ E-mail: nova_rati@y mail.com, hwu mmetro@g mail.com
}

\begin{abstract}
This study through 3 phases: definition, design phase and development phase. Definition and design phase starts from the formulation of the problem until the formation of the PPP-based worksheets. The development phase includes three steps, namely validation by expert teachers and 2 professors, product revision, and product testing. Validation is d one by experts didaktif test, technical test, and test construction. In each test showed the percentage of $\geq 90 \%$ with a very high category. Results of product testing data obtained legibility worksheets that get a percentage of $\geq 72 \%$ in each of the indicators with high $\geq$ categories. student activity sheet feasibility level percentage obtained by $\geq 70 \%$ in each category indicator with $\geq$ high. Level inquiry of students who achieved $\geq 82 \%$ showed results with very high category
\end{abstract}

Kata Kunci: inquiry, le mbar kerja siswa, student activity sheet

Kegiatan pembelajaran yang baik idealnya tidak selalu berpusat pada guru (teacher centered) tetapi berpusat kepada siswa (student centered) yang menekankan pada aktivitas siswa untuk mencari dan menemukan sendiri jawaban dari suatu masalah yang dipertanyakan. Pembelajaran inkuiri membutuhkan salah satu perangkat pembelajaran yang mendukung pelaksanaan pembelajaran agar mempermudah terhadap pemahaman materi pembelajaran yang didapat yaitu Lembar Kegiatan Siswa (LKS). Masalah yang melatarbelakangi penelitian ini adalah belum berkembangnya LKS di sekolah menjadi LKS yang inkuiri. Oleh karena itu, peneliti ingin melakukan pengembangan terhadap LKS tersebut menjadi LKS yang berbasis inkuiri. Menurut Sanjaya (2008:7) sistem pembelajaran adalah suatu kombinasi terorganisasi yang meliputi unsur-unsur manusiawi, material, fasilitas, perlengkapan dan prosedur yang berinteraksi untuk mencapai suatu tujuan. Unsur manusiawi dalam sistem pembelajaran terdiri atas siswa, guru/pengajar, serta orang-orang yang mendukung terhadap keberhasilan proses pembelajaran.

Pengajaran biologi melalui pendekatan inkuiri diharapkan dapat menjadi tempat bagi siswa untuk memecahkan masalah dan mempelajari dirinya sendiri serta alam sekitar. Sesuai dengan kurikulum 2013, inkuiri merupakan salah satu bentuk pendekatan ilmiah atau scientific approuch. Berdasarkan hasil observasi pada 23 Mei 2013 di SMAN 6 Metro, LKS yang ada di sekolah dari segi didaktif belum memenuhi semua indikator inkuri, dari segi konstruksi dan teknis masih perlu diperbaiki. 
Selama ini proses pembelajaran biologi hanya menekankan pada pemahaman konsep (kognitif), dan kurangnya penerapan melalui hasil penemuan serta pemecahan masalah melalui kegiatan praktikum secara langsung sehingga siswa kurang terlatih. Terkait dengan ini, maka penulis mengembangkan LKS Inkuiri. Dengan pembelajaran ini diharapkan memberi kemudahan bagi siswa dalam mempelajari pokok bahasan Keanekaragaman Hayati.

\section{METODE}

Jenis penelitian ini merupakan penelitian pengembangan (Research and Development), hal ini karena menge mbangkan produk LKS berbasis Inkuri yang di dalamnya terkandung indikator-indikator inkuiri. Menurut Thiagarajan dan Semmel (dalam Trianto, 2011:93) bahwa Model 4-D ini terdiri dari 4 tahap pengembangan, yaitu Define, Design, Develop, dan Desseminate atau diadaptasikan menjadi Model 4-P, yaitu Pendefinisian, Perancangan, Pengembangan, dan Penyebaran. Menurut Sugiyono (2011:407) hasil akhir dari kegiatan penelitian dan pengembangan adalah berupa desain produk baru, yang lengkap dengan spesifikasinya. Desain produk harus diwujudkan dalam gambar atau bagan, sehingga dapat digunakan sebagai pegangan untuk menilai dan membuatnya.

Sehingga pengembangan ini berbeda dengan penilitian pendidikan karena dalam penelitian pengembangan ini akan dihasilkan sebuah produk berdasarkan hasil temuan di lapangan. metode inkuiri terbimbing dalam penelitian ini adalah suatu metode untuk mengembangkan keingintahuan siswa dengan cara mengajukan permasalahan kepada siswa berupa pertanyaan untuk dipecahkan dan mengarahkan siswa agar mau menemukan sendiri jawaban atas permasalahan tersebut dengan cara membuat hipotesis, memperoleh data dengan melakukan pengamatan, memproses data dan menarik kesimpulan.

Penelitian ini melalui 3 tahap yaitu tahap pendefinisian, tahap perancangan dan tahap pengembangan. Tahap pendefinisian dan perancangan dimulai dari perumusan masalah hingga terbentuknya LKS berbasis Inkuiri. Setelah LKS yang dirancang sudah siap maka dilanjutkan ke tahap pengembangan. Sebelum diujicobakan di kelas, maka LKS akan divalidasi oleh tim ahli. Validasi oleh tim ahli ini dilakukan pada 3 uji yaitu uji didaktif, uji teknis, dan uji konstruksi. Tim ahli terdiri dari 1 guru dan 2 dosen. Validasi oleh guru Biologi dilaksanakan pada tanggal 10 Januari 2014. Validasi oleh dosen dilakukan pada tanggal 3 dan 4 Januari 2014.

Setelah validasi ahli selesai, maka LKS diujicobakan di kelas. Uji coba kelompok kecil dilakukan satu kali pertemuan, dan setelah itu LKS direvisi kembali dengan metode inkuiri materi Keanekaragaman Hayati Tingkat Gen dan Jenis dengan menggunakan LKS I. Pada pertemuan kedua dilaksanakan dengan metode inkuiri materi Keanekaragaman Hayati Tingkat Ekosistem dengan menggunakan LKS II. Pengambilan data keterbacaaan dan keterlaksanaan LKS melalui angket siswa dilakukan pada pertemuan kedua setelah pembelajaran selesai. Pengambilan 
data inkuiri dilakukan oleh observer yang mengamati kegiatan tiap siswa pada tiap pertemuan.

\section{HASIL}

Setelah melalui ketiga tahap pengujian ahli, dan didapatkan datanya, maka data tersebut dapat dianalisis. Pada LKS I didapatkan hasil uji didaktif sebesar $90 \%$. Hasil uji teknis menunjukkan persentase $93 \%$.
Hasil uji konstruksi juga menghasilkan persentase 98\%. Ketiga hasil uji tersebut dikategorikan "Sangat Tinggi". Pada LKS II didapatkan hasil uji didaktif sebesar 95\%. Hasil uji teknis menunjukkan persentase $95 \%$. Hasil uji konstruksi juga menghasilkan persentase 95\%. Ketiga hasil uji tersebut juga dikategorikan "Sangat Tinggi”.

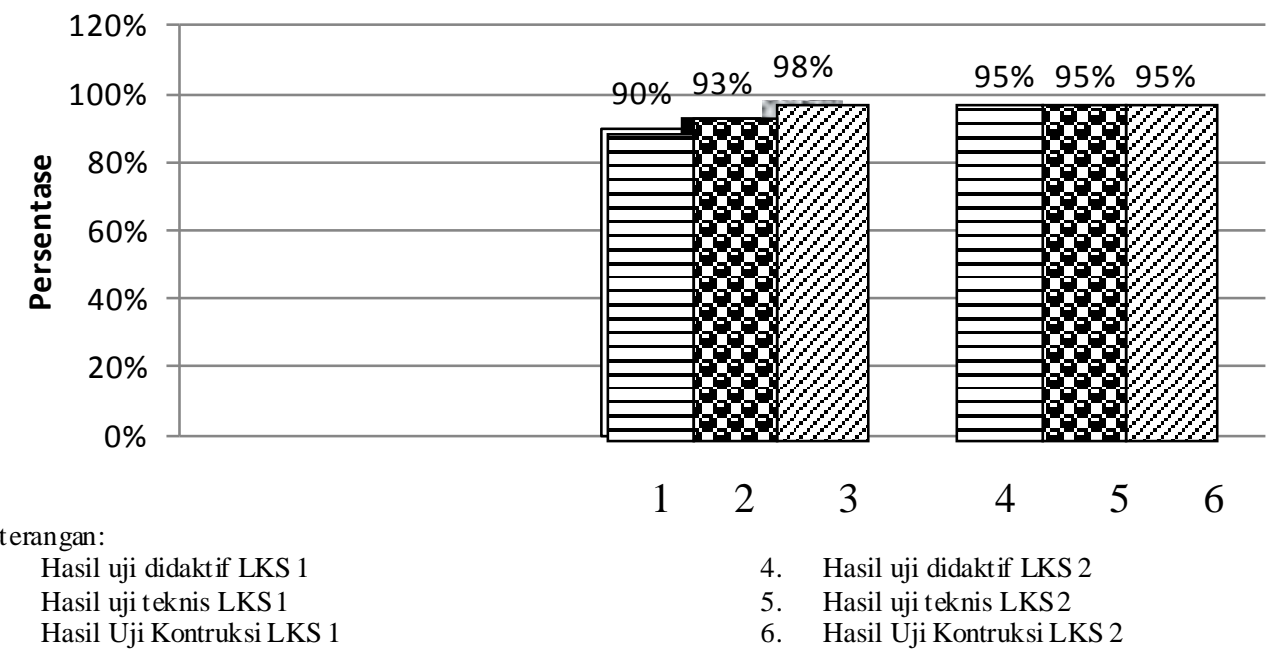

Gambar 1. Hasil Uji pada LKS I dan LKS II

Dari hasil analisis maka dapat disimpulkan bahwa LKS memiliki tingkat didaktif baik yang berarti mampu menjadi pedoman siswa dalam melakukan kegiatan inkuiri. LKS juga memiliki tingkat teknis baik yang berarti materi dalam LKS sudah sesuai dengan kebutuhan siswa. LKS juga memiliki tingkat konstruksi baik yang berarti memenuhi aturan dalam penyusunan LKS.
Analisisnya dari indikator ukuran huruf didapatkan hasil $94 \%$. Dari pemilihan kata hasilnya $94 \%$. Isi/pesan pada LKS sebesar $72 \%$. Bentuk dan cara penyajiannya $92 \%$. Gambar pada LKS sebesar 91\%. Dasar teori sebesar $84 \%$. Lembar hasil pengamatan sebesar 96\%. Petunjuk LKS sebesar 89\%. Cara pemberian LKS sebesar 96\%. Dan saran terhadap LKS sebesar $89 \%$. 
NOVARATI, A. \& HENING, W., PENGEMBANGAN LEMBAR ....

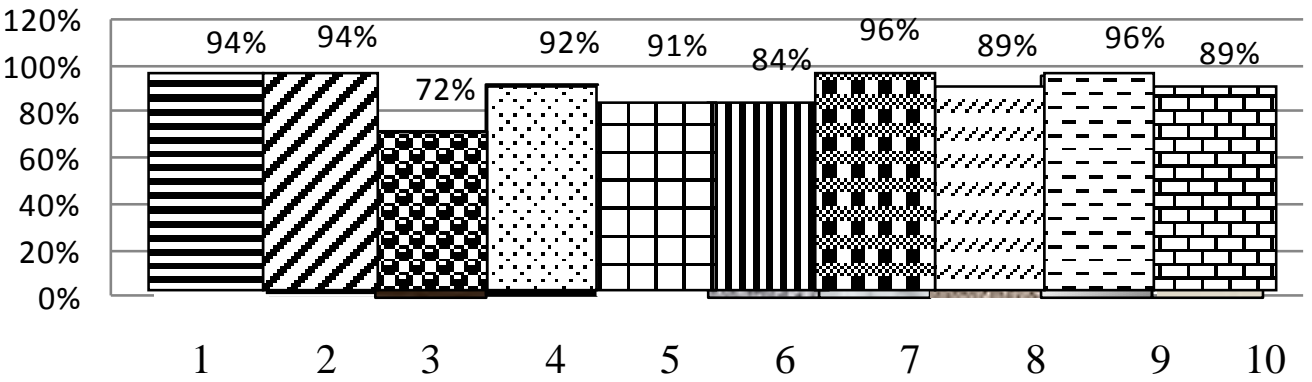

Keterangan:

$\begin{array}{ll}\text { 1. } & \text { Ukuran huruf } \\ \text { 2. } & \text { Pemilihan kata } \\ \text { 3. } & \text { Isi atau pesan } \\ \text { 4. } & \text { Bentuk dan cara penyajian } \\ \text { 5. } & \text { Gambar }\end{array}$

6. $\quad$ Dasar teori

7. Lembar hasil pengamatan

8. Petunjuk LKS

9. Cara memberikan LKS

Saran terhadap penerapan LKS

Gambar 2. Hasil Indikator pada LKS

Hasil dari keterlaksanaan LKS yaitu dari indikator perumusan masalah dan hipotesis sebesar $89 \%$. Dari kemudahan memperoleh data pengamatan sebesar $94 \%$. Pelaksanaan pengamatan sebesar $86 \%$. Kerja sama kelompok sebesar 94\%. Penyelesaian pertanyaan sebesar $91 \%$. Kemampuan mengkomunikasikan hasil sebesar 91\%. Literatur yang digunakan sebesar 78\%. Kemampuan menyimpulkan didapat sebesar $85 \%$. Pendapat mengenai inkuiri sebesar $93 \%$.

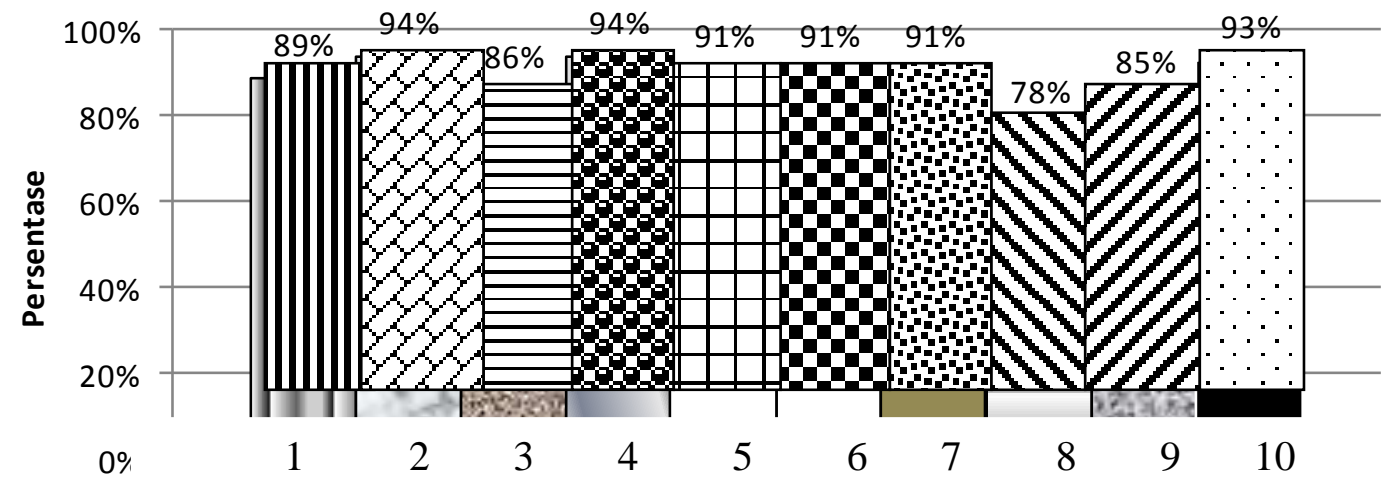

\footnotetext{
Keterangan:

1. Perumusan masalah dan hipotesis

2. Perolehan Data

3. Pelaksanaan pembelajaran

4. Kerja sama antar kelompok

5. Pengisian tabel hasil pengamat an
}
6. Penyelesaian pert anyaan
7. Kemampuan mengkomunikasikan hasil temuan.
8. Literature
9. Kemampuan unt uk menyimpulkan hasil temuan 10. Pendapat mengenai inkuri.

Gambar 3. Hasil Uji keterlaksanaan LKS

Kegiatan inkuiri dapat dinilai melalui observasi, dilakukan dengan melihat 5 indikator. Dari hasil observasi, Pada LKS I didapatkan hasil 
yaitu indikator merumuskan masalah sebesar $86 \%$. Indikator membuat hipotesis sebesar $82 \%$. Indikator mengumpulkan data melalui pengamatan sebesar 93\%. Indikator mengorganisasi data sebesar $98 \%$. Indikator dalam menyimpulkan sebesar $94 \%$.
Pada LKS II didapatkan indikator merumuskan masalah sebesar $82 \%$. Indikator membuat hipotesis sebesar 91\%. Indikator mengumpulkan data melalui pengamatan sebesar 94\%. Indikator mengorganisasi data sebesar $89 \%$. Indikator dalam menyimpulkan sebesar $96 \%$.

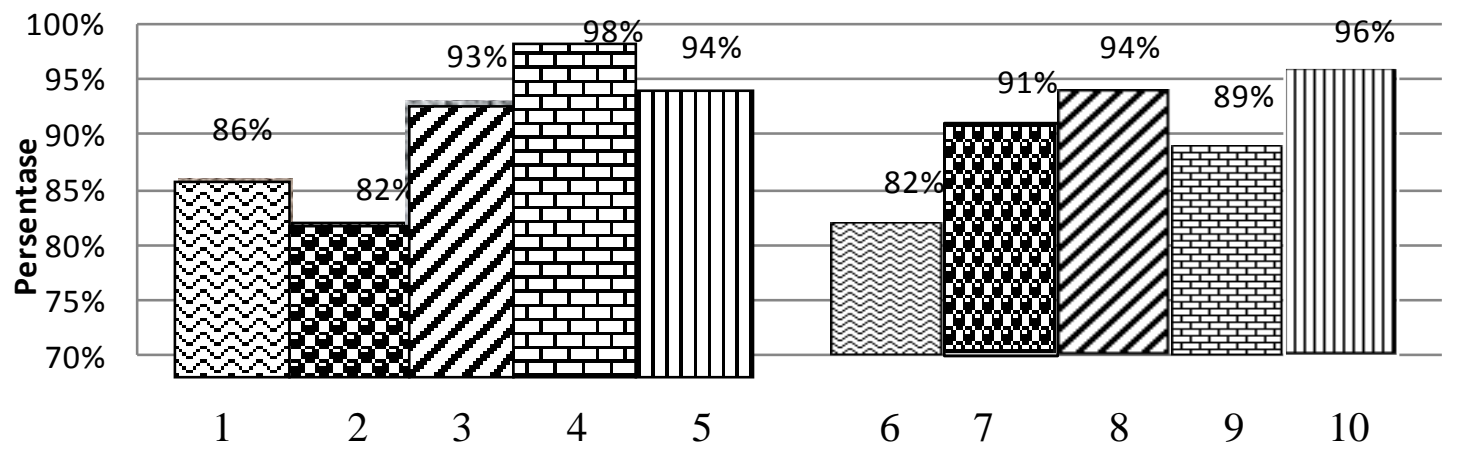

Keterangan:

1. Merumuskan masalah pada LKS 1

2. Merumuskan hipotesis pada LKS 1

3. Mengumpulkan dat a pada LKS 1

4. Organisasi data pada LKS 1

5. Menyimpulkan pada LKS 1

6. Merumuskan masalah pada LKS 2

7. Merumuskan hipotesis pada LKS 2

8. Mengumpulkan data pada LKS 2

9. Organisasi dat a pada LKS 2

10. Menyimpulkan pada LKS 2

Gambar 4. Hasil Uji inkuiri dapat dinilai melalui observasi, dilakukan dengan melihat 5 indikator

Model pendekatan inkuiri lebih menekankan pada siswa karena siswa dapat mencari, menemukan dan menyelesaikan masalah yang diberikan secara sistematis. Ditegaskan oleh Ridwan (2013:14), bahwa "Model pembelajaran inkuiri merupakan bentuk dari pendekatan pembelajaran yang berorientasi kepada siswa (student centered approach). Dikatakan demikian, karena dalam model ini siswa memegang peran yang saat dominan dalam proses pembelajaran".

\section{PEMBAHASAN}

Pada

Pelaksanaan pembelajaran di Sekolah memerlukan sumber belajar yang dapat mempermudah proses pembelajaran dan membantu siswa untuk mencapai tujuan dari proses pembelajaran. Menurut Karwono \& Mularsih (2010:133) bahwa Sumber belajar mempunyai peran yang sangat erat dengan pembelajaran yang dilakukan, dan pola-pola yang dilakukan oleh guru. Sumber belajar adalah segala sesuatu yang dimanfaatkan oleh seseorang mempelajari sesuatu. Sumber belajar meliputi: pesan, orang, bahan, alat, teknik dan latar. Sumber 
belajar dapat dibedakan menjadi yang didesain, dan sumber belajar yang dimanfaatkan.

Dalam pemanfaatan sumber belajar, guru mempunyai tanggung jawab membantu peserta didik agar belajar lebih mudah, lebih lancar, lebih terarah. Oleh sebab itu guru dituntut untuk memiliki kemampuan khusus yang berhubungan dengan pemanfaatan sumber belajar. Herdianawati dkk (2013:99) menyebutkan "salah satu perangkat pembelajaran yang dapat memberikan manfaat bagi guru dan siswa adalah Lembar Kegiatan Siswa (LKS). LKS berbasis inkuiri yang dikembangkan oleh peneliti telah mengikuti beberapa syarat sesuai dengan pendapat Arafah dkk (2012:90) bahwa dalam penyusunan LKS terdapat beberapa syarat yaitu syarat didaktif, kontruksi dan teknis.

Pembelajaran inkuiri terbimbing lebih mengajak siswa melakukan serangkaian kegiatan fisik maupun mental (kognitif). Siswa diminta untuk memahami atau merumuskan: masalah, tujuan, dan hipotesis. Siswa melakukan pengamatan atau penyelidikan, mencari data, menganalisis permasalahan yang telah dirumuskan. Berdasarkan pendapat Trianto (2011:114) bahwa: "Inkuiri merupakan bagian inti dari kegiatan pembelajaran berbasis kontekstual. Pengetahuan dan keterampilan yang diperoleh siswa diharapkan bukan hasil mengingat seperangkat faktafakta, tetapi hasil dari menemukan sendiri”. Hal tersebut sesuai dengan penelitian yang telah dilakukan bahwa LKS berbasis inkuiri yang digunakan lebih mengutamakan pada hasil sumber belajar temuan dari lingkungan yang ada di sekitar sekolah.

Setelah melewati hasil Tahap uji coba dilakukan melalui 3 tahap yaitu uji perseorangan atau uji ahli, uji coba kelompok kecil dan uji coba lapangan. Validasi ahli dilakukan dengan uji didaktif, uji teknis, dan uji konstruksi. Pada masing-masing uji didapatkan hasil persentase $\geq 90 \%$ dengan kategori sangat tinggi. Hasil dari uji coba produk didapatkan data bahwa keterbacaan LKS mendapatkan persentase sebesar $\geq 72 \%$ pada tiap indikatornya dengan kategori $\geq$ tinggi. Tingkat keterlaksanaan LKS didapatkan persentase sebesar $\geq 78 \%$ pada tiap indikatornya dengan kategori $\geq$ tinggi. Proses inkuiri yang dicapai siswa menunjukkan hasil $\geq 82 \%$ dengan kategori sangat tinggi. Berdasarkan data hasil penelitian bahwa LKS yang dikembangkan peneliti sudah baik dan layak digunakan dalam pembelajaran di kelas.

\section{KESIMPULAN}

Dari keseluruhan uji coba produk terlihat hasil keterbacaan LKS, keterlaksanaan pembelajaran, dan hasil kegiatan inkuiri yang dicapai siswa berada pada nilai di atas rata-rata yaitu $\geq 70 \%$ dan berada pada kategori tinggi. Berdasarkan hal ini maka dapat disimpulkan bahwa peneliti tidak akan melakukan revisi/perbaikan dari produk hasil pengembangan. Produk pengembangan sudah baik dan layak digunakan dalam pembelajaran di kelas dan dapat diterima dengan baik oleh siswa kelas X di SMAN 6 Metro. 


\section{SARAN}

LKS berbasis inkuiri ini memiliki keterbacaan, keterlaksanaan dan pencapaian inkuiri yang tinggi maka peneliti menyarankan kepada para guru untuk mampu mengembangkan LKSnya menjadi LKS yang berinkuiri pada tiap materi yang membutuhkan pada hasil penemuan khususnya pada praktikum yang dapat menguatkan teori.

\section{DAFTAR RUJUKAN}

Arafah Ferdiana Sherlly, Priyono Bambang, Ridlo Saiful. 2012. Pengembangan LKS Berbasis Berpikir Kritis Pada Materi Animalia.Unnes Journal of Biology Education 1 (1).page 7581

Herdianawati, Savitri, Herlina Fitrihidajati, Tarzan Purnomo. 2013. Pengembangan Lembar Kegiatan Siswa (LKS) Inkuiri Berbasis Berfikir Kritis pada Materi Daur Biogeokimia Kelas
X. BioEdu Vol.2/No.1/Januari 2013. Page 99 of 104.

Karwono, \& H. Mularsih. 2010. Belajar dan Pembelajaran serta Pemanfaatan Sumber Belajar. Ciputat: Cerdas Jaya.

Ridwan, Avizena. 2013. Penerapan Model Pembelajaran Inkuiri pada Tema Pencemaran Air untuk Meningkatkan Ketuntasan Hasil Belajar Siswa Di Kelas VII SMP Negeri 2 Buduran Sidoarjo. Jurnal Pendidikan Sains e-pensa Vol.01/No.01/Januari 2013. Page 13 of 17.

Sanjaya, Wina. 2008. Perencanaan dan Desain Sistem Pembelajaran. Jakarta: Kencana, Prenada Media Group.

Sugiyono. 2011. Metode Penelitian Pendidikan Pendekatan Kuantitatif, Kualitatif, dan $R \& D$. Bandung: Alfabeta.

Trianto. 2011. Mendesain Model Pembelajaran Inovatif-Progresif. Jakarta: Bumi Aksara.

Trianto. 2011. Model Pembelajaran Terpadu. Jakarta: Bumi Aksara 